Article

\title{
Challenges in Training and Educational Innovation: An Evaluative Perspective of the Digital Teaching Competence in the Context of a Pandemic
}

\author{
Alba Ruth Pinto Santos ${ }^{1}$, Carlos Enrique George-Reyes ${ }^{2, *}$ and Omar Fernando Cortés-Peña ${ }^{3}$ \\ 1 Faculty of Educational Sciences, University of La Guajira, Colombia; arpinto@uniguajira.edu.co \\ 2 Tecnologico de Monterrey, Escuela de Humanidades y Educación, Ave. Eugenio Garza Sada 2501, \\ Monterrey 64849, NL, Mexico Monterrey 64849, Mexico; cgeorge@tec.mx. \\ 3 Department of Psychology, University Sergio Arboleda, Colombia; omar.cortes@correo.usa.edu.co \\ * Correspondence: cgeorge@tec.mx
}

\begin{abstract}
This article analyzes the assessment of the four development levels of the Digital Teaching Competence (DTC) to recognize the needs and formulation of challenges in training and educational innovation required in the pedagogical practices of university professors under the current context of the Covid-19 pandemic. The study used an empirical-analytical methodology with a nonexperimental, transactional, descriptive design. The sample design was probabilistic, estimated with $95 \%$ confidence and 5\% error among 252 teachers from various faculties of the University of La Guajira. The selected instrument corresponded to the rubric's application to evaluate the university professor's digital teaching competence in Latin America. Among the study's significant results, we highlight that the rubric presented a high Cronbach's alpha reliability ( $\alpha$ : 0.947$)$. In the general assessment of DTC development, it was estimated that $78.2 \%$ of teachers are in the first two levels of DTC development assessment (Beginning and Middle). The evaluation rubric allows identifying challenges and opportunities that teacher training must address to advance the professional development of professors.
\end{abstract}

Keywords: Digital Teaching Competence (DTC), higher education; continuing teacher education; educational innovation

\section{Introduction}

The health and educational crisis caused by the appearance and expansion of the Severe Acute Respiratory Syndrome Corona-virus-2 (SARS-CoV-2) produced new challenges for Higher Education [1]. One of them was the urgency to launch the Digital Teaching Competence (DTC) to guarantee the continuity of the teaching and learning processes [2]. Another was to analyze the international frameworks, models, standards, uses, innovation, and appropriation of digital technologies in improvement processes and teacher training. In this sense, continuing teacher training must respond to the challenges of professional training and improve skills so that teachers can diversify and be change agents, knowing how to teach using digital technology creatively and innovatively [3].

The development of the DTC is essential for the improvement and quality of higher education since the dynamics of teaching and learning require a teacher specialized in their area of knowledge to link the use of digital technology to the pedagogical processes [4-6]. In this sense, 
acquiring the DTC makes it possible to transform teaching methodologies and innovatively use digital technology in pedagogical processes [7-9].

The pandemic caused by Covid19 forced educational institutions to go through three stages of change: reaction, emergency management, and planning of the "new normal" [10], where the mediation of the pedagogical practices through digital technology ceased to be perceived as complementary or even unnecessary training. On the contrary, to understand the quality of education, whether face-to-face, virtual, or mixed, one must develop digital competencies [11]. Therefore, information and communication technologies (ICT) have become allies of the teacher since they serve as facilitating tools in the teaching-learning processes. In the permanent training of teachers, they strengthen participation, collaboration, and teamwork in the knowledge society and innovation in educational practices [12].

This leads to questioning whether the levels of DTC that teachers have shown have been sufficient to face the emerging challenges in education. It has raised the need to investigate strengthening teachers' ICT competencies to improve professional practice [13]. It has also highlighted the importance of transforming training contexts, where the teachers have the knowledge and skills to leverage digital technology in the design of learning practices, complemented with the support of various resources, symbolic systems, and training actions [14-16]. Due to Covid19, the development of DTC became a priority to generate learning environments responding to the challenges of educational innovation, the construction of knowledge, and the creative development of individuals in education [17]. Furthermore, given the imminent appearance of hybrid educational models in the coming post-pandemic stage, it is urgent to incorporate the assessment of teacher competencies [18].

In this regard, the development of DTC is a gradual action that goes from the instrumental management of ICT to the transformation of the teacher's professional practice [19]. In higher education, each dimension of DTC affects practices related to content management [20], the design of teaching-learning processes [21], the development of projects with ICT [22], collaborative work [23], and permanent and continuous training of teachers [24], among others.

In designing training processes to promote the professional appropriation of digital technology, higher education educational institutions should consider analyzing the results of DTC evaluations, offering incentives to reduce hours, improve salaries, and offer other awards [25]. Thus, the purpose of this study was to assess the levels of development of DTC in university teachers to recognize the needs and formulation of challenges in training and educational innovation required in their pedagogical practices, attending to the present and future needs of post-pandemic education.

\section{Materials and Methods}

The methodological approach to the study was empirical-co-analytical with a non-experimental, transactional, descriptive design and an 
evaluative instrumental function [26-27]. The study was empiricalanalytical because it was supported with valid and reliable instruments; it was not experimental because the independent variables were not manipulated. Its scope is descriptive because it focuses on the central problem to evaluate the levels of development of DTC with the protocol established in the selected rubric.

\section{Sample}

The population was comprised of 1,344 full-time professors from the University of La Guajira in Colombia. For the development of the study, a probabilistic sample design was assumed with a 95\% confidence level, 5\% error, and an estimated proportion (p: 0.72) based on the distribution of teachers by their academic load. Consequently, the study sample had 252 teachers, $56.1 \%$ women and $43.9 \%$ men. The age ranges of the sample participants were: 1) $34.4 \%$ between 40 to 49 years old; 2) $28.1 \%$ between 50 to 59 years old; 3 ) $25.6 \%$ between 30 to 39 years old; 4 ) $6.7 \%$ over 60 years old, and 5) 5.2\% under 25 years old. The sample characterization of Faculty participation was $35.8 \%$ by the Faculty of Economic and Administrative Sciences, 26\% Education Sciences, 23.5\% Social and Human Sciences, 11.9\% Engineering, and $2.5 \%$ Basic and Applied Sciences.

\section{Instrument}

The instrument selected to evaluate DTC was a questionnaire called "Rubric to evaluate the digital competence of the university professor in Latin America" [28]. The selected rubric was comprised of four dimensions, as described in Table 1:

Table 1. Multidimensional Structure of the Rubric to evaluate the DTC of the University Professor.

\begin{tabular}{lcc}
\hline DTC Evaluation Dimension & Descriptors & Specifications \\
\hline $\begin{array}{c}\text { D1. Didactics, curricular and } \\
\text { methodological }\end{array}$ & 6 & $\begin{array}{c}\text { Teaching planning, digital competence, technol- } \\
\text { ogy and learning, information management, di- } \\
\text { versity, monitoring, tutoring, and academic } \\
\text { evaluation. }\end{array}$ \\
\hline $\begin{array}{c}\text { D2. Planning, organization, and } \\
\text { management of digital technol- } \\
\text { ogy resources spaces }\end{array}$ & 5 & $\begin{array}{c}\text { Learning environments, factors associated with } \\
\text { the management, infrastructure, incorporation, } \\
\text { and use of digital technologies. }\end{array}$ \\
\hline $\begin{array}{c}\text { D3. Relational, ethics, and secu- } \\
\text { rity }\end{array}$ & 5 & $\begin{array}{c}\text { Ethics, inclusion, institutional digital identity, } \\
\text { dissemination, and transfer of knowledge with } \\
\text { the educational community. }\end{array}$ \\
\hline $\begin{array}{c}\text { Mechanisms of free access, creation, and sociali- } \\
\text { zation of educational resources mediated by }\end{array}$ \\
digital technology in virtual learning communi- \\
ties.
\end{tabular}

Source: Own elaboration derived from the rubric structure to evaluate the university professor's digital competence in Latin America [28].

In total, 21 items were addressed with the rubric, each item a different descriptor indicator, enabling a classification to be adapted to generate the assessment. The rubric consists of four levels of development of the Digital Teaching competence, (N1) representing the lowest level and (N4) the one with the most significant advance. The complete categorization is as follows: Beginner Level (N1), Medium Level (N2), Expert Level (N3), and 
Transformer Level (N4). The scores derived from the rubric's 21 items presented a Cronbach's alpha reliability level of 0.947. Additionally, all the items generated positive correlations with the general scale and ranged between r: 0.537 and r: 0.724 .

Process

The procedure of this study was carried out in four stages, which are described below:

Instrument selection: First, the data collection instrument was selected after analyzing and evaluating 52 articles in a systematic review of the literature on Digital Teaching Competence [29]. It was determined to apply the rubric to evaluate the TDC of university professors in Latin America.

Selection of participants: Initially, the information of the full-time teaching staff at the University of La Guajira (N: 1,344) was requested, and the sample size $(n=252)$ was estimated. Subsequently, a systematic and random selection procedure was established for teachers within each campus and faculty.

Rubric application. The study's nature, objective, and scope were presented to the selected teachers, and their informed consent form was requested. Subsequently, the digitalized version of the rubric was administered and applied online with Google Forms by those responsible for the educational technology training process, thus counting on the participation of the teachers in various administrations and faculties of the university.

Analysis of data. In this phase, the data of the digital application was exported in spreadsheet format (Excel) to carry out preliminary data validation. Subsequently, the file was exported to the SPSS version 21 program to advance the statistical processing and analysis of the results. The statistical techniques applied were descriptive analysis, reliability analysis, correlational analysis, and comparative analysis. These analyses provided the evidence that later made it possible to generate the study's conclusion.

\section{Results}

The main findings derived from the rubric application are presented below. Figure 1 presents the profile of the participants concerning the level of training; $57.9 \%$ of the teachers had a master's degree, $19.5 \%$ had a specialization, $13.9 \%$ had doctoral training, and $8.7 \%$ only had an undergraduate degree.

Doctorate

Masters

Specialization

Undergraduate
$13.9 \%$ 
Figure 1. Profile of the participants' training levels.

Next, Figure 2 presents the assessment profile of the $1^{\text {st }}$ Dimension: Didactic, curricular, and methodological. On a scale of 1 to 4 rating the DTC development level established for each of the six rubric indicators, the highest the indicator of digital technologies as learning facilitators had the highest mean (2.61), followed by teaching planning and digital competence (2.40), and information processing and knowledge creation (2.36). The lowest indicator for Dimension 1 was attention to diversity (2.05).

The above confirms that the abrupt change from face-to-face to nonface-to-face educational settings caused teachers to assess technological resources to design lessons and activities that strengthen learning and its dissemination positively [30] and make precise planning of teaching activities. However, the design of inclusive teaching strategies remains a pending task.

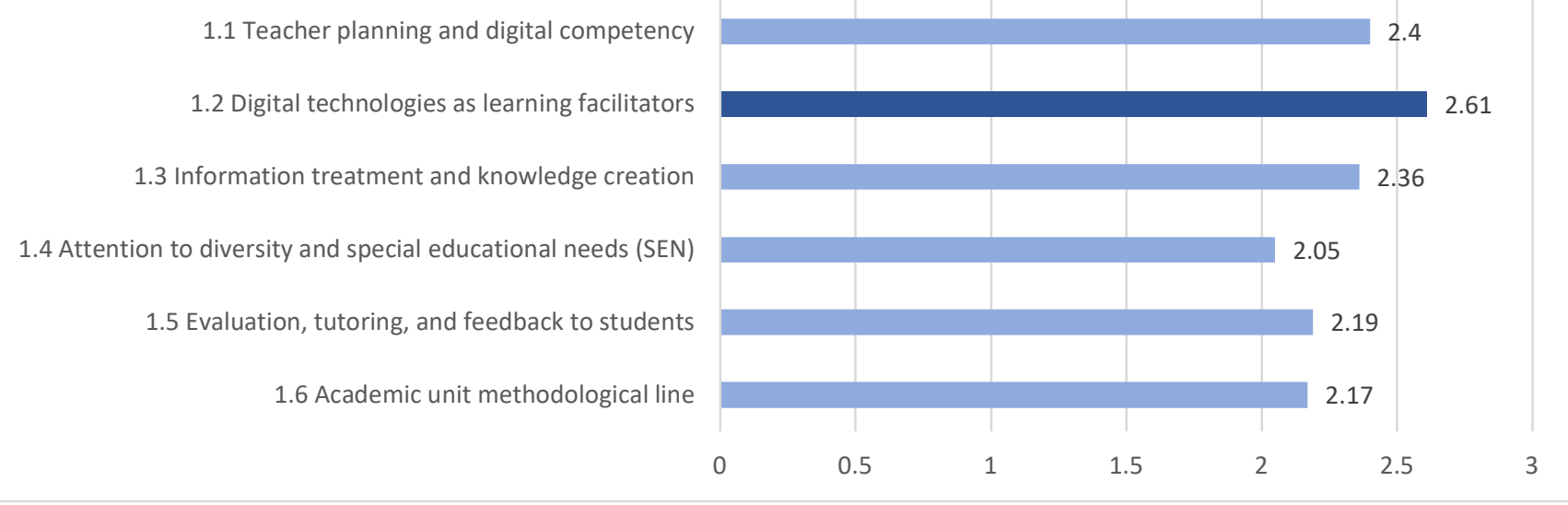

Figure 2. Assessment profile of the $1^{\text {st }}$ Dimension: Didactic, curricular, and methodological.

Figure 3. presents the evaluation profile of the 2nd Dimension: Planning, organization, and management of digital technological spaces and resources. The highest evaluation was achieved by the institution's digital technologies management indicator (2.31), followed by institutional spaces with digital technologies (2.26). The lowest indicator for this dimension was projects incorporating digital technologies (1.51). .

The above assessments indicate that although there is a general uncertainty regarding the opportunities for access to the digital infrastructure [31], there is also adequate management of teachers' technological resources. Likewise, a culture of leveraging technology has been developing positively, favoring the appropriation of the digital skills necessary to use communication tools and digital platforms. Also, during the pandemic, many teachers were exposed to education measured by technologies [32]. 


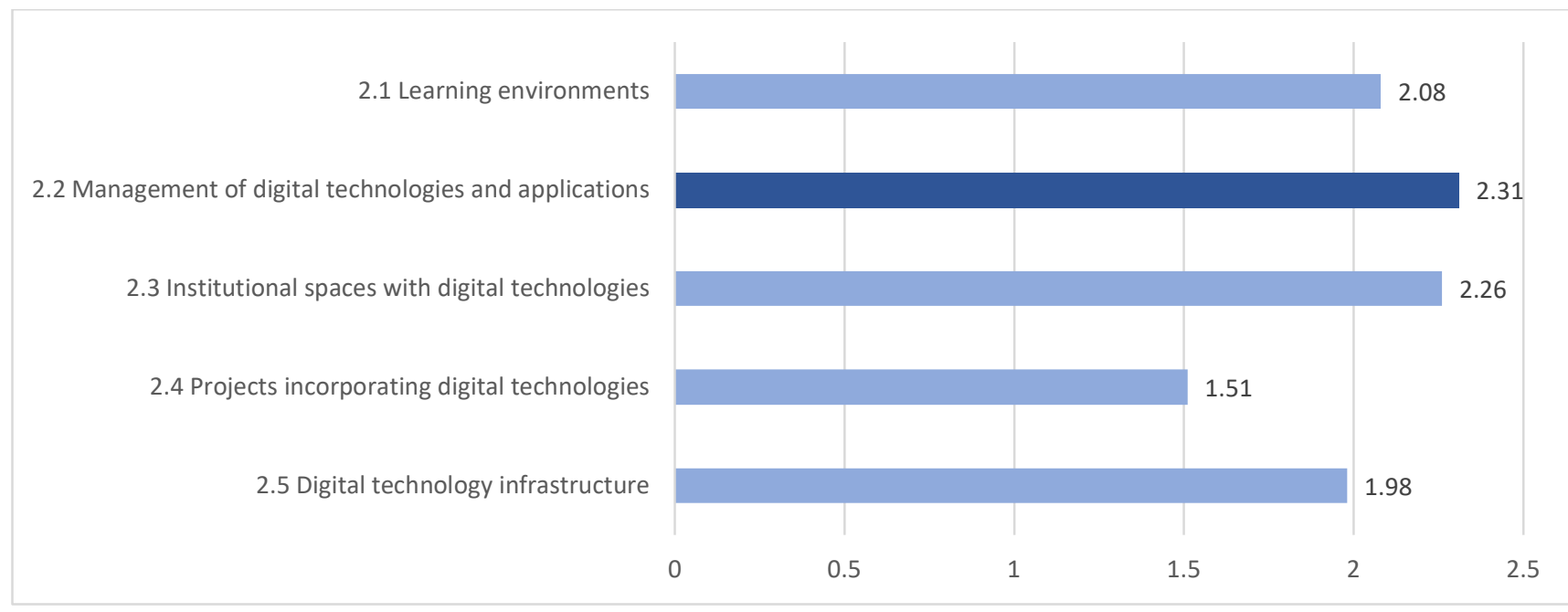

Figure 3. Assessment profile of 2nd Dimension: Planning, organization, and management of digital technology spaces and resources.

Figure 4 shows the assessment profile of the 3rd Dimension: Relational, ethics, and safety, in which assessments below (2.0) were obtained. The ethical and safety indicator was the highest valuation (1.98), followed by digital inclusion (1.85). The indicator communication and knowledge transfer obtained (1.64) had the lowest valuation within the dimension. These results show that in the environment of a pandemic caused by COVID-19, where academic activities have been carried out in the remote mode, it is not enough to handle devices and computer programs properly, but also requires the ability to guarantee their safety when using them [33]. In addition, considering that the new educational models point to a hybrid modality, the teachers must be prepared to use their devices safely [34].

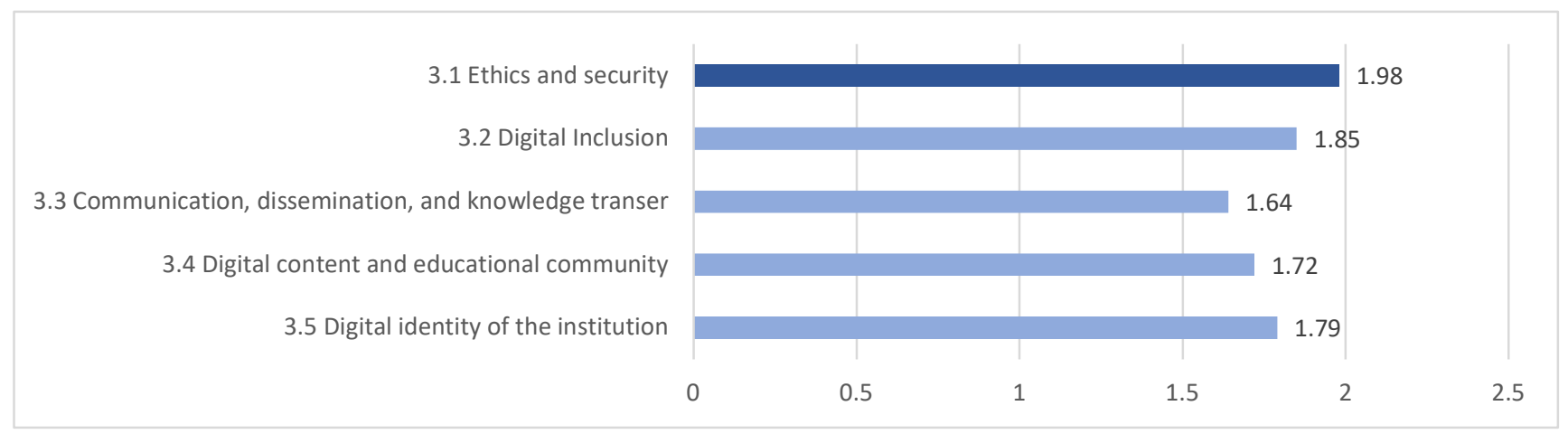

Figure 4. Assessment profile of 3rd Dimension: Relational, ethics, and security.

Finally, Figure 5 shows the assessment profile of the 4th Dimension: Personal and professional, which had a rating of 1.98 for the permanent training indicator and 1.93 for virtual learning communities. The indicators with the lowest value in this dimension were personal learning environment (1.56) and access to information, creation, and dissemination of didactic material with open licenses (1.67).

Regarding permanent training, various authors state that to evaluate training experiences, at least three sets of competencies must coexist. The first is communicative interaction [35], which refers to the teacher's ability 
to communicate synchronously, mainly through videoconferences [36] and asynchronously through educational platforms [37]. The second relates to the teacher's ability to select and use resources that arise from the interweaving of image, video, sound, and interactivity, ideal digital materials to facilitate teaching and learning processes [38]. The third refers to the need for teachers to use a wide range of applications and software designed for assessment that offer different ways of measuring the same learning situation [39].

In the face of emerging teaching modalities, the results suggest that teacher training requires these three sets of digital competencies. What emerged due to Covid19 as a temporary solution for an unexpected teaching situation is now seen as an alternative to expand learning contexts in the short and medium terms [40].

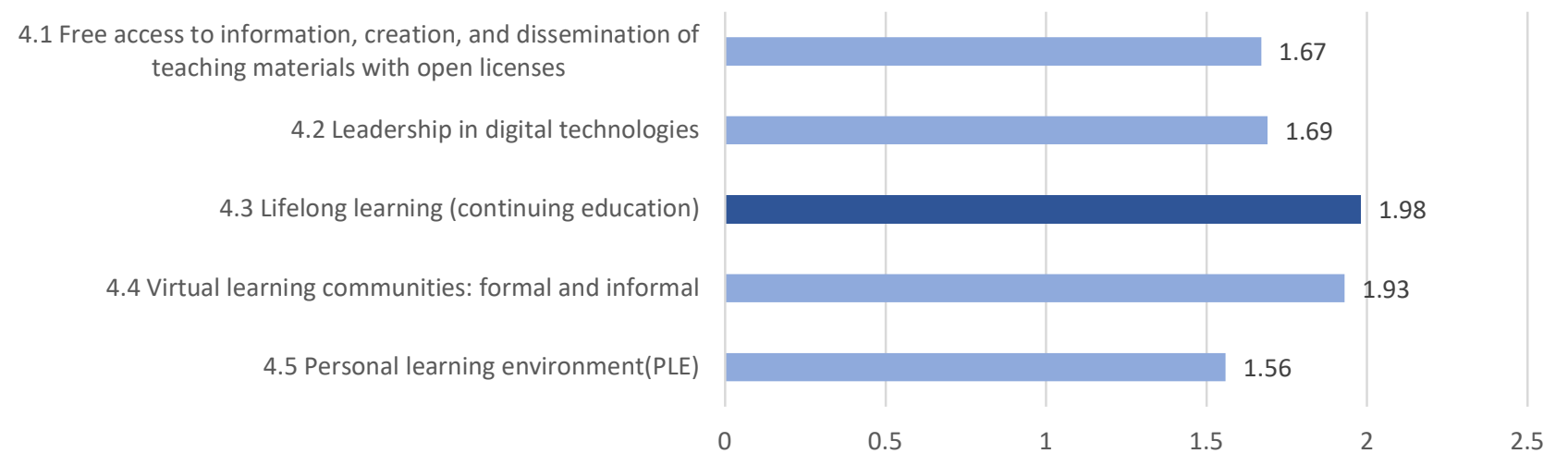

Figure 5. Assessment profile of the 4th Dimension: Personal and professional.

Figure 6 presents the comparative analysis of the mean scores per DTC dimension, using a 1 to 4 scale, where (1) is the lowest and (4) the highest assessment level of DTC development. In this case, the Digital Teaching Competence Scale presents an average of (1.99). Complementarily, within this general profile, D1 (Curricular and methodological teaching) presents the highest average level (2.30), followed by D2 (Planning, organization, and management of spaces and technological resources) with 2.03, then D3 (Relational, ethics and security) (1.80) and, finally, D4 (Personal and professional) (1.77). 


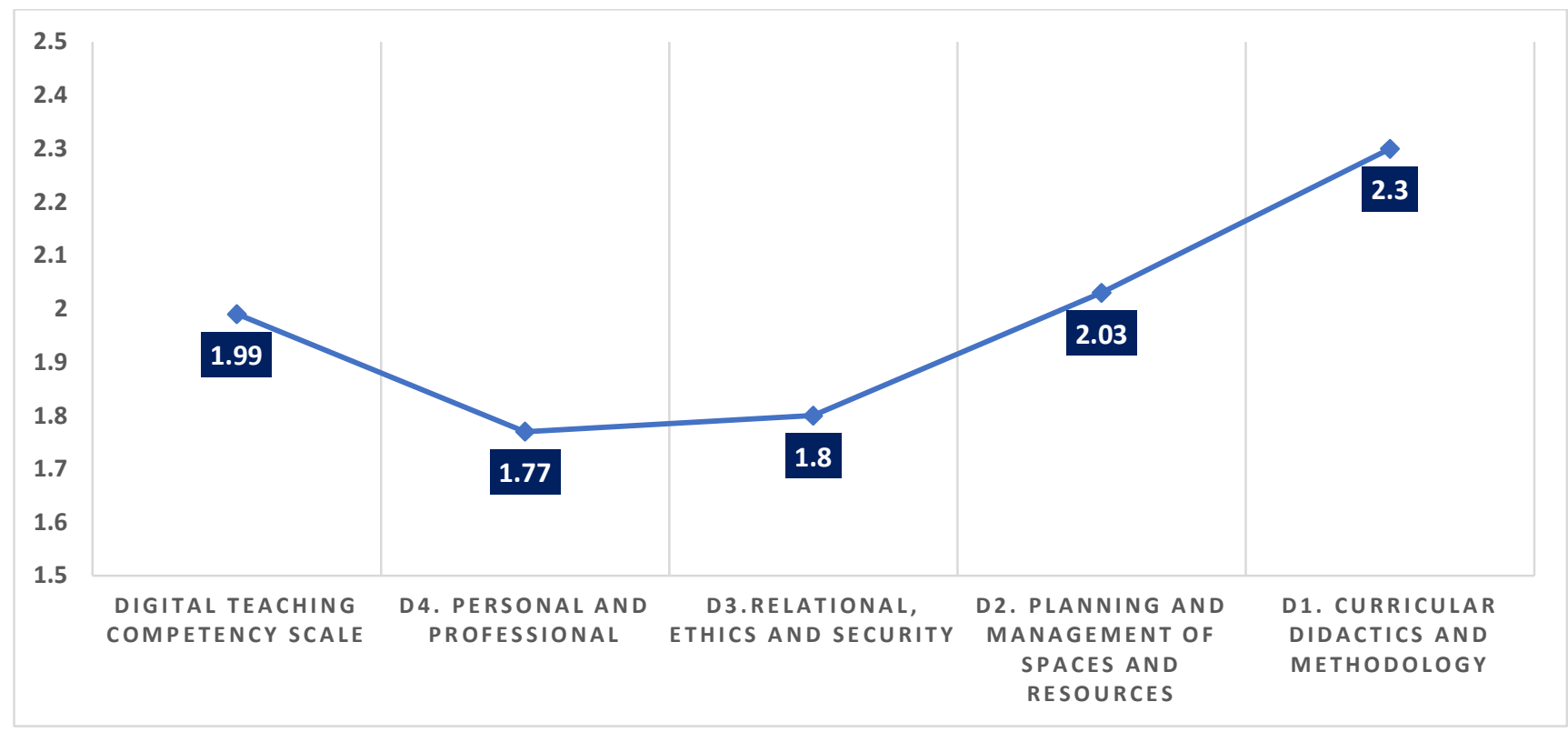

Figure 6. Comparative analysis of DTC scores by dimension (on a 1 to 4 scale).

From the rubric scores, we generated the four classification ranges corresponding to the levels of DTC development. Figure 7 shows the synthesis derived from the general assessment of the teachers who participated in the study, showing DTC concentrated in the Beginner (40.5\%) and Medium (37.7\%) levels. The figure also shows that only $16.3 \%$ of the teachers attained Expert level and just $5.6 \%$ the Transformative level.

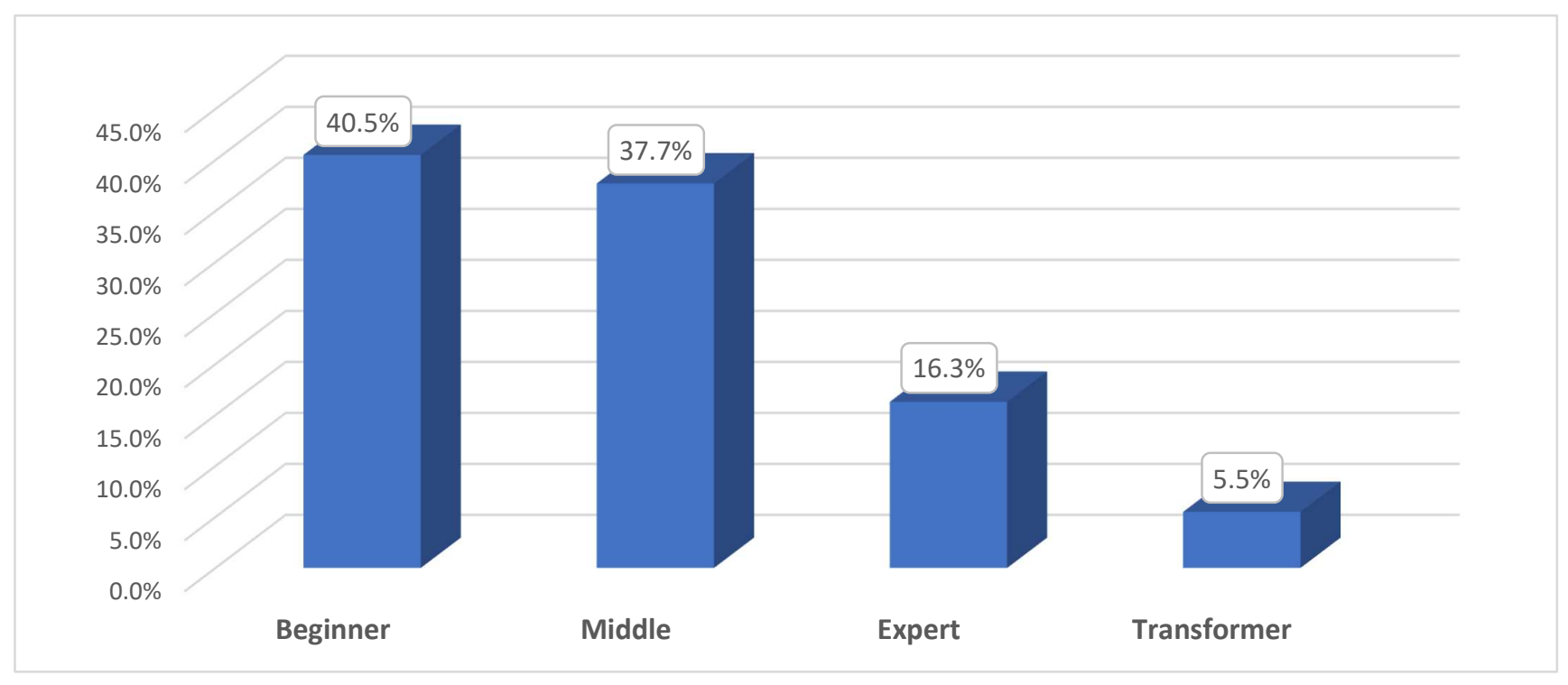

Figure 7. General profile of DTC development in university teachers.

Finally, Table 2 presents the comparative analysis of the DTC development levels reported by teachers and faculty, according to the dimensions of the rubric used. Note that the teachers in the Faculty of Engineering attained the highest levels of DTC. One-third were classified in the Medium level; one-third were classified Expert, and 11.1\% attained Transformer level. 
In the Faculty of Economic and Administrative Sciences, $48.9 \%$ were classified as Beginners, 33.3\% Medium, 14.4\% Expert, and 3.3\% Transformer. Most teachers in the Faculty of Education Sciences were classified at the Beginner level (36.6\%) and medium (36.6\%). Social Sciences and Basic Sciences obtained the lowest performances among the faculties; $37.9 \%$ and $66.7 \%$ of the teachers were classified at the Beginner level, and $48.3 \%$ and $33.3 \%$ Medium, respectively.

Table 2. Comparative analysis of the levels of development of the DTC by faculty and dimension.

\begin{tabular}{|c|c|c|c|c|c|c|c|}
\hline \multirow{2}{*}{\multicolumn{2}{|c|}{ Levels of Competence }} & \multicolumn{6}{|c|}{ Faculty } \\
\hline & & $\begin{array}{c}\text { Economic and Ad- } \\
\text { ministrative Sci- } \\
\text { ences }\end{array}$ & Engineering & $\begin{array}{c}\text { Social and } \\
\text { Human Sci- } \\
\text { ences }\end{array}$ & $\begin{array}{c}\text { Basic and Ap- } \\
\text { plied Sci- } \\
\text { ences }\end{array}$ & $\begin{array}{l}\text { Education Sci- } \\
\text { ences }\end{array}$ & Total \\
\hline \multirow{5}{*}{$\begin{array}{l}1^{\text {st }} \text { Dimension: } \\
\text { Curricular and } \\
\text { Methodological } \\
\text { Didactics }\end{array}$} & Beginner & $32.2 \%$ & $11.1 \%$ & $32.8 \%$ & $33.3 \%$ & $26.8 \%$ & $28.6 \%$ \\
\hline & Medium & $32.2 \%$ & $33.3 \%$ & $41.4 \%$ & $66.7 \%$ & $33.8 \%$ & $35.7 \%$ \\
\hline & Expert & $30 \%$ & $33.3 \%$ & $17.2 \%$ & $0 \%$ & $26.8 \%$ & $25.8 \%$ \\
\hline & Transformer & $5.6 \%$ & $22.2 \%$ & $8.6 \%$ & $0 \%$ & $12.7 \%$ & $9.9 \%$ \\
\hline & Total & $100 \%$ & $100,0 \%$ & $100 \%$ & $100 \%$ & $100 \%$ & $100 \%$ \\
\hline \multirow{5}{*}{$\begin{array}{l}2^{\text {nd }} \text { Dimension: } \\
\text { Planning Organi- } \\
\text { zation and Man- } \\
\text { agement }\end{array}$} & Beginner & $36.7 \%$ & $14.8 \%$ & $29.3 \%$ & $33.3 \%$ & $31.0 \%$ & $31.0 \%$ \\
\hline & Medium & $47.8 \%$ & $44.4 \%$ & $55.2 \%$ & $66.7 \%$ & $43.7 \%$ & $48.4 \%$ \\
\hline & Expert & $14.4 \%$ & $25.9 \%$ & $13.8 \%$ & $0 \%$ & $16.9 \%$ & $15.9 \%$ \\
\hline & Transformer & $1.1 \%$ & $14.8 \%$ & $1.7 \%$ & $0 \%$ & $8.5 \%$ & $4.8 \%$ \\
\hline & Total & $100 \%$ & $100 \%$ & $100 \%$ & $100 \%$ & $100 \%$ & $100 \%$ \\
\hline \multirow{5}{*}{$\begin{array}{l}3^{\text {rd }} \text { Dimension: } \\
\text { Ethics and Secu- } \\
\text { rity }\end{array}$} & Beginner & $633 \%$ & $44.4 \%$ & $53.4 \%$ & $100 \%$ & $46.5 \%$ & $55.2 \%$ \\
\hline & Medium & $21.1 \%$ & $11.1 \%$ & $37.9 \%$ & $0 \%$ & $29.6 \%$ & $25.8 \%$ \\
\hline & Expert & $12.2 \%$ & $25.9 \%$ & $5.2 \%$ & $0 \%$ & $16.9 \%$ & $13.1 \%$ \\
\hline & Transformer & $3.3 \%$ & $18.5 \%$ & $3.4 \%$ & $0 \%$ & $7.0 \%$ & $6.0 \%$ \\
\hline & Total & $100 \%$ & $100 \%$ & $100 \%$ & $100,0 \%$ & $100,0 \%$ & $100,0 \%$ \\
\hline \multirow{5}{*}{$\begin{array}{l}4^{\text {th }} \text { Dimension: } \\
\text { Personal and Pro- } \\
\text { fessional }\end{array}$} & Beginner & $63.3 \%$ & $29.6 \%$ & $50.0 \%$ & $83.3 \%$ & $46.5 \%$ & $52.4 \%$ \\
\hline & Medium & $26.7 \%$ & $44.4 \%$ & $37.9 \%$ & $16.7 \%$ & $33.8 \%$ & $32.9 \%$ \\
\hline & Expert & $10 \%$ & $18.5 \%$ & $6.9 \%$ & $0 \%$ & $15.5 \%$ & $11.5 \%$ \\
\hline & Transformer & $0 \%$ & $7.4 \%$ & $5.2 \%$ & $0 \%$ & $4.2 \%$ & $3.2 \%$ \\
\hline & Total & $100 \%$ & $100 \%$ & $100 \%$ & $100 \%$ & $100 \%$ & $100 \%$ \\
\hline \multirow{5}{*}{ General Scale } & Beginner & $48.9 \%$ & $22.2 \%$ & $37.9 \%$ & $66.7 \%$ & $36.6 \%$ & $40.5 \%$ \\
\hline & Medium & $33.3 \%$ & $33.3 \%$ & $48.3 \%$ & $33.3 \%$ & $36.6 \%$ & $37.7 \%$ \\
\hline & Expert & $14.4 \%$ & $33.3 \%$ & $12.1 \%$ & $0 \%$ & $16.9 \%$ & $16.3 \%$ \\
\hline & Transformer & $3.3 \%$ & $11.1 \%$ & $1.7 \%$ & $0 \%$ & $9.9 \%$ & $5.6 \%$ \\
\hline & Total & $100 \%$ & $100 \%$ & $100 \%$ & $100 \%$ & $100 \%$ & $100 \%$ \\
\hline
\end{tabular}

The results presented above are consistent with the contributions of other researchers [6] [16] [19] [25], who also identified that engineering teachers are those who have achieved the highest evaluations in the levels of DTC. In our study, note that most participants in the Faculty of Engineering were classified in the Medium and Transformer dimensions, obtaining an average on the general scale of 2.34. Even when comparing the results with the Faculty of Education Sciences, they attained higher means in all dimensions. For example, for the 1st dimension, Curricular and Methodological Didactics, the Faculty of Engineering obtained a valuation of 2.77, and the Faculty of Education attained 2.35.

\section{Discussion}

The findings derived from evaluating the teachers' DTC development levels at the University of La Guajira constitute a starting point for identifying the primary needs and challenges in training, research, and 
educational innovation mediated by digital technology. In this study, $78.2 \%$ of teachers were in the first two levels of assessment (Beginner and Middle); only $16.3 \%$ of teachers managed to reach the expert level, and just $5.6 \%$ of the teachers achieved the transformative level. Thus, we observe the need to strengthen DTC training and development processes in the most critical dimensions and indicators.

The results show that the professors in the Faculty of Engineering tend to have a higher valuation, even in the 1st Dimension, Curricular and Methodological Didactics. Thus, it is necessary to analyze the conceptions of Digital Teaching Competence and the assessment differences in the light of technology, information literacy, and educational and critical use of ICT [41].

The Faculty of Education must develop training processes that promote advances in DTC levels. It is essential to transform educational scenarios to focus on constructing knowledge, where learners incorporate and model DTC development processes in future teachers [42-43].

It should be noted that having an excellent disposition and management of technology influences the development of other dimensions of DTC. Reflection on the results generates a lesson learned. It is essential to consider the area of knowledge as a factor of the development potential of DTC and the institutional agenda for teacher training in the world of technologies. Digital and educational innovation should consider transversal and interdisciplinary spaces to promote synergistic encounters of expertise and knowledge for integrity in the quality of higher education [44].

On the other hand, this study found no significant differences regarding age, even though it has been affirmed that age is a differentiator in developing digital competence [45]. This leads us to reflect that the different dimensions of DTC go beyond the instrumental use of virtual devices and tools. There may be synergistic strengths in younger teachers to combine knowledge, skills, and attitudes that allow the appropriation of digital technology to innovate educational practice.

It is also observed that $57.9 \%$ of teachers have a master's degree and $13.9 \%$ a doctorate, which is not synonymous with their expertise in developing DTC. This finding is important, given that it implies generating not only a series of reflections on the importance of developing DTC but also incorporating institutional guidelines and transversal curricular updating in high-level training programs (master's and doctorate).

\section{Conclusions}

The reflections of the results obtained from this study are articulated with the lessons learned and contributions from different authors that highlight the need to strengthen training in DTC. This strengthening must find the balance between the online and face-to-face environments, establishing synergistic links for learning and developing professional skills. It is a central challenge for the present and future of educational innovation in higher education in each institution's particular, local and regional contexts. The strengthening must occur to face the problems, 
uncertainty, and challenges of the education sector, in a world currently in crisis due to the pandemic [46].

Based on the primary needs identified in the DTC evaluation, the following challenges of training, innovation, and pedagogical strengthening of teachers were formulated:

- Strengthening skills in the use, creation, and reuse of personalized materials and resources to meet the diverse educational needs of students and the inequalities in using digital technology.

- Implementing pedagogical practices using digital resources for tutoring, observing, evaluating, and monitoring progress in student learning.

- Training and promoting the effective, critical, and creative use of digital technologies responsibly, safely, and maintaining ethical treatment of information and respect for copyrights.

- Implementing personalized accompaniment procedures for continuous improvement, management, monitoring, and evaluation of DTC in teacher performance.

- Developing digital competence in both teachers and students, supported by the design of virtual and learning environments and excellent management of communication, dissemination, innovation, social appropriation, and knowledge transfer processes.

- Formulating, managing, and evaluating projects to incorporate digital technologies to strengthen educational innovation.

- Understanding DTC as a requirement for the development of the teaching profession requires the educational institution to support the training processes, create conditions for the appropriation of educational technology, and manage resources to generate these change processes.

- Thinking about the development of DTC requires teachers' commitment, will, and involvement in transforming the teaching role in the digital age.

The formulation of the challenges is complemented by the need for permanent technological and pedagogical support for teachers through training and support spaces that fundamentally favor the transition to current learning scenarios. The results of this study coincide with those of other authors [47-48], highlighting the lessons learned from virtual and hybrid learning models that have been implemented or strengthened to face the challenges of higher education in pandemic times. Higher education institutions must prioritize the active role of teachers in training to take on the challenges of research and pedagogical innovation in the digital world.

Finally, it was verified that the rubric to evaluate the digital competence of the university professors in the Latin American context [28] was a valid instrument because it included four fundamental DTC dimensions in the professional teaching exercise. It was not limited to evaluating the capabilities versus instrumental use of educational technology. In this sense, the descriptors in the DTC levels classifying each indicator of the evaluation rubric became fundamental when designing the 
teacher training process. The dimensions of the evaluation instrument were constituted considering the analysis and formulation of challenges in DTC and educational innovation.

The study limitations include that the self-reports formulated by the teachers in the DTC evaluation rubric may present slight bias in some cases because the teacher confuses the disposition and handling of ICT with feeling competent in critically using and appropriating digital technology for professional improvement. It should be noted that this sensitivity to bias is not significant, as the results do not present an overvaluation effect because most of the teachers were categorized in the Beginner and Medium levels $(78.2 \%)$.

\begin{abstract}
Author Contributions: Conceptualization, software, formal analysis, research, data preservation, data curation, ARPS, methodology, validation, writing-original draft, CEGR; drafting-reviewing and editing, visualization, supervision, project management, ARPS; CEGR; OFCP All authors have read and accepted the published version of the manuscript.
\end{abstract}

Funding: This research did not receive external funding. The APC was funded by the Institute for the Future of Education - Tecnológico de Monterrey.

Acknowledgments: The authors wish to acknowledge the financial and technical support of the Writing Lab, Institute for the Future of Education, Tecnologico de Monterrey, Mexico, in the production of this work.

Conflicts of Interest: The authors declare that they have no conflict of interest.

\title{
References
}

[1] Means, B.; Neisler, J. Teaching and learning in the time of COVID: The student perspective. Onl. Lear. 2021, 25(1), 8-27. doi: 10.24059/olj.v25i1.2496

[2] Murphy, M. COVID-19 and emergency eLearning: Consequences of the securitization of higher education for post-pandemic pedagogy. Cont. Sec. Pol. 2020, 41(3), 492-505. doi: 10.1080/13523260.2020.1761749

[3] Amaya, A.; Zúñiga, E.; Salazar, M.; Ávila, A. Empower teachers in their academic work through International Certifications in Digital Competencies. Apert. 2020, 10(1), 104-115, 2018. doi: 10.18381/ap.v10n1.1174

[4] Hepp, K.; Prats, M.; Holgado, J. Formación de educadores: la tecnología al servicio del desarrollo de un perfil profesional innovador y reflexivo. RUSC Rev. Univ Soc. Con. 2015, 12(2), 30-43. https://bit.ly/3jkJ5Xu

[5] Admiraal, W.; van Vuget, F.; Kranenburg, F.; Koster, B.; Smit, B.; Weijers, S. Preparing pre-service teachers to integrate technology into K-12 instruction: Evaluation of a technology-infused approach. Technology. Pedag. Educ. 2016, 26(1), 105-120. doi: 10.1080/1475939X.2016.1163283

[6] Cabero, J.; Palacios, A. Digital Competence Framework for Educators «DigCompEdu». Translation and adaptation of «DigCompEdu Check-In» questionnaire. EDMETIC. Rev. Educ. Med. TIC. 2020, 9(1), 213-234. doi: 10.21071/edmetic.v9i1.12462

[7] Pinto, A; Cortés, O.; Alfaro, C. Towards the transformation of teaching practice: spiral model of competences TIC-TAC-TEP. Píxel-Bit. Rev. Med. Educ. 2017, 51, 1-13. doi: 10.12795/pixelbit.2017.i51.03

[8] Bustos, H.; Gómez, M. La competencia digital en docentes de preparatoria como medio para la innovación educativa. CPU-e. Rev. Inv. Educ. 2018, 26, 66-86. doi: 10.25009/cpue.v0i26.2544

[9] Baz, E.; Balçıkanlı, C.; Cephe, P. Introducing an innovative technology integration model: Echos from ELF pre-service teachers. Educ. Inf. Tech. 2018, 23, 2179-2200. doi: 10.1007/s10639-018-9711-9

[10] Agasisti, T.; Soncin, M. Higher education in troubled times: On the impact of Covid-19 in Italy. Stud. Hig. Educ. 2021 46(1), 8695. doi: 10.1080/03075079.2020.1859689

[11] Cabero, J. Aprendiendo del tiempo de la COVID-19. Rev. elec. Educare. 202o, 24, 1-3. doi: 10.15359/ree.24-s.2

[12] Pinto, A.; Pérez, A.; Darder, A. Autopercepción de la competencia digital docente en la formación inicial del profesorado de educación infantil. Rev. Esp. 2020, 41(18), 10-32. http://www.revistaespacios.com/a20v41n18/20411829.html

[13] López, J.; Moreno, A.; Pozo, S.; López, J. Effect of digital teaching competence in the use of blended learning in Vocational Training. Inv. Bib. Aarch. Bibl. Inf. 2020, 34(83), 187-205. doi: 10.22201/iibi.24488321xe.2020.83.58147

[14] Aldosemani, T. Inservice teachers' perceptions of a professional development plan based on the SAMR model: A case study. The Turk. O. J. Educ. Tech. 2019, 18(3), 46-53. http://www.tojet.net/articles/v18i3/1834.pdf

[15] Çetin, E. Digital storytelling in teacher education and its effect on the digital literacy of pre-service teachers. Thin. Sk. Creat. 2021, 39, 1-13. doi: 10.1016/j.tsc.2020.100760

[16] Cabero, J.; Guillén, F.; Ruiz, J.; Palacios, A. Digital competence of higher education professors according to DigCompEdu. Statistical research methods with ANOVA between fields of knowledge in different age ranges. Educ Inf Technol. 2021, 26, 46914708. doi: 10.1007/s10639-021-10476-5 
[17] Ando, S. University teaching and learning in a time of social distancing: A sociocultural perspective. J. Hum. Beh. Soc. Env, 31, 435-448. doi: 10.1080/10911359.2020.1814928

[18] Eringfeld, S. Higher education and its post-coronial future: Utopian hopes and dystopian fears at Cambridge university during covid-19. Stud. Hig. Educ. 2021, 46(1), 146-157. doi: 10.1080/03075079.2020.1859681

[19] Cabero, J.; Martínez, A. Information and Communication Technologies and initial teacher training. Digital models and competences. Prof. Rev. Curr. Form. Prof. 2019, 23(3), 247-268. doi: 10.30827/profesorado.v23i3.9421

[20] Pozo, S.; López, J.; Rodríguez, A.; López, J. Teachers' digital competence in using and analytically managing information in flipped learning. Cult. Educ. 2020, 32(2), 213-241, 2020. 10.1080/11356405.2020.1741876

[21] Esteve, F.; Castañeda, L.; Adell, J. A Holistic Model of Teaching Competence for the Digital World. Rev. Inter. Form. Prof. 2018, 91, 105-116. http://repositori.uji.es/xmlui/handle/10234/174771

[22] Padilla, A.; Gámiz, V.; Romero, M. Evolución de la competencia digital docente del profesorado universitario: incidentes críticos a partir de relatos de vida. Educar, 2020, 56(1), 109-27. doi: 10.5565/rev/educar.1088

[23] Tejada, J.; Pozos, K. Nuevos escenarios y competencias digitales docentes: hacia la profesionalización docente con TIC. Prof. Rev. Curr. Form. Prof. 2018, 22(1), 25-51. http://hdl.handle.net/10481/52320

[24] Falcó, J. Assessment of Digital Competence in Teachers in the Autonomous Community of Aragon. Rev. Elec. Inv. Educ. 2017, 19(4), 73-83. doi: 10.24320/redie.2017.19.4.1359

[25] Cabero, J.; Romero, R.; Barroso, L.; Palacios, A. Digital Teaching Competences Frameworks and the Suitability of University and Non-university Teachers. Rev. Car. Inv. Educ. 2020, 4 (2), 137-158. doi: 10.32541/recie.2020.v4i2.pp137-158

[26] León, O.; Montero, J. Métodos de investigación en psicología y educación. 2003, McGraw-Hill Interamericana.

[27] Valenzuela, J.; M. Flores, M. Fundamentos de Investigación Educativa. 2012, Editorial Digital del Tecnológico de Monterrey.

[28] Lázaro, J.; Gisbert, M.; Silva, J. A rubric to evaluate the digital competence of the university Teacher in the Latin American context. Edutec, Rev. Elec. Tec. Educ. 2018, 0(63), 1-14. 2018. doi: 10.21556/edutec.2018.63.1091

[29] Pinto, A.; Pérez, A.; Darder, A. Revisión sistemática de la literatura sobre competencia digital docente en la formación inicial del profesorado En La tecnología como eje del cambio metodológico. 2020, 513-517, UMA Editorial.

[30] Brown, C.; Salmi, J. Putting fairness at the heart of higher education. University World News. The Global Window on Higher Education. 2020. https://www.universityworldnews.com/post.php?story=20200417094523729

[31] Rodicio, M.; Ríos de Deus, M.; Mosquera, M.; Abilleira, M. La brecha digital en estudiantes Españoles ante la crisis de la COVID19. Rev. Inter. Educ. Just. Soc. 2020, 9(3), 103-125. doi: 10.15366/RIEJS2020.9.3.006

[32] Dvir, N.; Schatz, O. Novice teachers in a changing reality. Eur. J. Teac. Educ. 2020, 43(4), 639-656. doi: 10.1080/02619768.2020.1821360

[33] Tomczyk, L. What do teachers know about digital safety? Comp. Sch. 2019, 36(3), 167-187. doi: 10.1080/07380569.2019.1642728

[34] Rodríguez de Dios, I.; Igartua, J. Skills of digital literacy to address the risks of interactive communication. J. Inf. Tech. Res. 2018, 9(1), 621-632, 2018. doi: 10.4018/JITR.2016010104

[35] Octaberlina, L.; Muslimin, A. Efl students perspective towards online learning barriers and alternatives using moodle/google classroom during covid-19 pandemic. Int. J. Hig. Educ. 2020, 9(6), 1-9. doi: 10.5430/ijhe.v9n6p1

[36] Fatani, T. Student satisfaction with videoconferencing teaching quality during the COVID-19 pandemic. BMC Med. Educ. 2020, 20(1). doi: 10.1186/s12909-020-02310-2

[37] Daniel, S. Education and the COVID-19 pandemic. Prospects. Comparative Journal of Curriculum. Lear. Asse. 2020, 48(1), 1-2, 1-6. doi: 10.1007/s11125-020-09464-3

[38] Sepúlveda, P.; Morrison, A. Online teaching placement during the COVID-19 pandemic in Chile: Challenges and opportunities. Eur. J. Teac. Educ. 2020, 43(4), 587-607. doi: 10.1080/02619768.2020.1820981

[39] García, F.; Corell, A.; Abella V.; Grande, M. Online Assessment in Higher Education in the Time of COVID-19. EKS Educ. Know. Soc. 2020, 21, 1-26. doi: 10.14201/eks.23013

[40] Maier, V.; Alexa, L.; Craciunescu, R. Online education during the COVID19 pandemic: Perceptions and expectations of Romanian students. Proc. Eur. Conf. e-Lear. 2020, 317-324. doi: 10.34190/EEL.20.147

[41] List, A.; Brante, E.; Klee, H. A framework of pre-service teachers' conceptions about digital literacy: Comparing the United States and Sweden. Comp. Educ. 2020, 148. doi: 10.1016/j.compedu.2019.103788

[42] Borthwick, A.; Hansen, R. Digital literacy in teacher education. Are teacher educators competent? J. Dig. Lear. Tea. Educ. 2017, 33(2), 46-48. 2017. doi: 10.1080/21532974.2017.1291249

[43] Graziano, K.; Herring, H.; Carpenter, K.; Smaldino, S.; Finsness, E. A TPACK diagnostic tool for teacher education leaders. TechTrends. 2017, 61, 372-379. doi: 10.1007/s11528-017-0171-7

[44] Kimmons, R.; Hall, C. How useful are our models? Pre-service and practicing teacher evaluations of technology integration models. TechTrends. 2018, 62, 29-36. doi: 10.1007/s11528-017-0227-8

[45] Lara, J.; Cabero, J. Digital knowledge in higher education teachers. Study in a Mexican school. Rev. Educ. Dis. RED. 2021, 21(66), 2-19. doi: 10.6018/red.447911

[46] Kuhfeld, M.; Soland, J.; Tarasawa, B.; Johnson, A.; Ruzek, E.; J. Liu, J. Projecting the potential impact of COVID-19 school closures on academic achievement. Educ. Res. 2021, 49(8), 549-565. doi: 10.3102/0013189X20965918

[47] Rodríguez, C.; Fueyo, A.; Hevia I. The digital skills of teachers for innovating in university teaching. Píxel-Bit. Rev. Med. Educ. 2021, 61, 71-97. doi: 10.12795/pixelbit.86305

[48] Álvarez, Q.; López, S.; Parada, A.; Goncalvez, D. Cultura profesional y TIC en la formación del profesorado en tiempos de crisis: La percepción de los docentes. Rev. Elec. Inter. Form. Prof. 2021, 24(2), 153-165. doi: 10.6018/REIFOP.470831 